\title{
“SE ESTAVA TUDO BEM, PORQUE É QUE EU HAVIA DE IR \\ A UMA OBSTETRA?" \\ Identidade, risco e consumo de tecnologia médica no parto domiciliar em Portugal
}

\author{
Mário J. D. S. Santos \\ Instituto Universitário de Lisboa (ISCTE-IUL), CIES-IUL, Lisboa, Portugal
}

Amélia Augusto

Universidade da Beira Interior, Covilhã, Portugal

Instituto Universitário de Lisboa (ISCTE-IUL), CIES-IUL, Lisboa, Portugal

\begin{abstract}
Resumo O parto domiciliar contemporâneo é um fenómeno raro, pouco visível e, enquanto terreno empírico, é pouco explorado. Partindo de entrevistas a mulheres e casais que experienciaram um parto em casa planeado, o artigo pretende fornecer um primeiro retrato sociológico do fenómeno em Portugal. Este surge não como um retorno ao tradicional ou uma procura de uma experiência mística, mas antes como um acontecimento físico concreto, grandemente enformado por conhecimento científico e médico, que se inscreve numa procura de coerência identitária. Emergiram diversas perceções de risco social e de risco médico, tornando-se visível um consumo reflexivo de tecnologias médicas modelado por essas mesmas perceções. Ainda que destitua algum do protagonismo da medicina na gravidez e no parto, de facto não pode dizer-se que se trate de um fenómeno de desmedicalização.
\end{abstract}

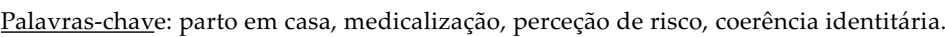

Abstract Contemporary home births are rare and quite invisible phenomena, and quite unexplored as an empirical field. From interviewing women and couples who experienced a planned home birth, this article aims to give an initial sociological portrait of this phenomenon in Portugal. It is shown to be not a return of the traditional or a search for a mystical experience, but rather a physical and concrete happening, strongly shaped by scientific and medical knowledge, within a search for identity coherence. Several social and medical risk perceptions emerged, as well as a reflexive consumption of medical technologies framed by these same perceptions. Despite the fact that home birth detracts the relevance of medicine during pregnancy and birth, it is not possible to frame it as a phenomenon of demedicalisation.

Keywords: home birth, medicalisation, risk perception, identity coherence.

Résumé L'accouchement à domicile contemporain est un phénomène rare, peu visible et en tant que terrain empirique il est peu exploré. À partir d'entretiens avec des femmes et des couples qui ont vécu un accouchement programmé à la maison, l'article prétend fournir un premier portrait sociologique de ce phénomène au Portugal. Celui-ci apparaît, non comme un retour au traditionnel ou comme la recherche d'une expérience mystique, mais plutôt comme un évènement physique concret, énormément formé par la connaissance scientifique et médicale, qui s'inscrit dans une recherche de cohérence identitaire. Diverses perceptions de risque social et médical ont surgi, ce qui a permis l'analyse d'une consommation réfléchissante de technologies médicales modelées par ces perceptions. Bien que l'accouchement à domicile enlève de l'importance à la médecine de la grossesse et de l'accouchement, on ne peut cependant pas dire qu'il s'agisse d'un phénomène de démédicalisation.

Mots-clés: accouchement à domicile, medicalisation, perceptions de risque, cohérence identitaire.

Resumen El parto domiciliario contemporáneo es un fenómeno raro, poco visible y como terreno empírico está poco explorado. Partiendo de entrevistas a mujeres y parejas que han experimentado un parto en casa planificado, el artículo pretende mostrar un primer retrato sociológico del fenómeno en Portugal. Este surge, no como un regreso a lo tradicional o una búsqueda de una experiencia mística, sino como un acontecimiento físico concreto extremadamente enmarcado por el conocimiento científico y médico, que se inscribe en la búsqueda de una coherencia identitaria. Surgieran diferentes percepciones de riesgo social y riesgo médico, y un consumo reflexivo de las tecnologías médicas modelado por estas percepciones. Aunque 


\section{Introdução}

Enquanto fenómeno social, o parto hospitalar contemporâneo ilustra, de forma paradigmática, os modos como os valores médicos e masculinos se sobrepõem aos valores leigos e femininos. Na gravidez e no parto, a medicalização - projeção social da ampliação do poder da medicina - não pode ser analisada apenas como uma mera replicação de um fenómeno, num campo mais restrito da realidade. A afirmação da medicina sobre o corpo da mulher assenta em bases mais amplas de género e de dominância social do masculino sobre o feminino.

Os movimentos pró-desmedicalização do parto, reclamando neste o protagonismo perdido pela mulher e pela família, divulgam e apoiam o direito à prática de alternativas ao parto hospitalar padronizado, como o parto em casa. Esta opção, relativamente rara em Portugal e nos restantes contextos europeus (Euro-Peristat, 2013), tem vindo a emergir em debates académicos, clínicos e mediáticos que discutem a sua segurança e legalidade, bem como a impreparação do sistema de saúde português para dar uma resposta adequada ao reduzido - mas relevante número de casos que se registam no país. Dados do Instituto Nacional de Estatística ${ }^{1}$ revelam que, nos últimos dez anos, os partos em casa constituíram, em média, 0,75\% do total de partos. Em 2013, dos 83.121 partos registados, 592 foram partos domiciliares. Estes são dados limitados, uma vez que não é possível distinguir entre os partos domiciliares planeados e os acidentais, duas situações extremamente diferentes quanto às condições de segurança, aos riscos envolvidos (Olsen e Clausen, 2012) e mesmo às motivações e características sociodemográficas maternas.

A partir de um estudo exploratório ${ }^{2}$ de cariz intensivo, procurou-se analisar a experiência da mulher ou do casal que viveu o parto em casa por opção, em Portugal, desde o conhecimento dessa possibilidade, passando pela vigilância da gravidez, o planeamento e a experiência do parto, até à fase pós-parto. Um olhar sobre a diversidade de percursos e as diferentes perceções de risco que são associadas à gravidez e ao parto hospitalar ou em casa tornou visíveis os fatores sociais que estão na base da rejeição da assistência hospitalar predominante. Emergiram dinâmicas singulares nas relações de confiança estabelecidas entre a mulher grávida e os restantes atores que intervêm no acompanhamento e vigilância da gravidez, o que se reflete nos modos como a tecnologia (médica, ou não) e os restantes recursos são

1 Disponíveis em www.ine.pt.

2 Este artigo tem por base a dissertação de mestrado em Saúde, Medicina e Sociedade, intitulada Nascer em Casa - A Desinstitucionalização Reflexiva do Parto no Contexto Português, apresentada em 2012 e disponível em http://hdl.handle.net/10071/4684. 
dotados de um valor simbólico e mobilizados ou rejeitados durante o processo. Estas características particulares permitiram traçar um primeiro retrato sociológico do parto domiciliar contemporâneo em Portugal.

\section{Alguns referenciais teóricos para uma sociologia crítica do nascimento e da maternidade}

O parto é hoje amplamente aceite como pertencendo ao domínio pericial e é mesmo definido, frequentemente e de forma imprecisa, como um ato médico. ${ }^{3}$ Consequentemente, a personagem principal da história reprodutiva da mulher deixa definitivamente de ser ela própria e passa a ser a figura patriarcal do profissional de saúde (Campbell e Porter, 1997; Carapinheiro, 2005 [1993]) que, pela sua autoridade científica, lhe vigia a saúde para que se mantenha dentro da normalidade e lhe faz o parto. Foucault (1994 [1976]: 107) descreve especificamente este controlo como a "histerização do corpo da mulher", um processo triplo segundo o qual o corpo da mulher foi analisado, integrado como uma doença intrínseca na ciência biomédica e colocado em contacto e comunicação com o social, o familiar e o materno, numa lógica de manutenção da espécie.

Apesar de diferirem no seu contexto, muitos dos estudos que abordam de forma crítica o parto medicalizado afirmam que o parto, um evento fisiológico, tem sido analisado e assumido pela medicina como envolto em riscos, deixando a mulher à margem das tomadas de decisão e das ações sobre o seu próprio corpo, descaracterizando uma experiência que se poderia dizer naturalmente promotora do empowerment individual da mulher (Fox e Worts, 1999). No entanto, considerar as mulheres apenas como vítimas passivas do controlo tecnológico masculino é ignorar elementos relevantes da sua participação no processo de medicalização e contribuir para o reforço do estereótipo da mulher vítima e passiva (Petchesky, 1987; Riessman, 1994). Se é um facto que movimentos feministas têm vindo a desenvolver críticas à medicalização no sentido de se diminuírem as diferenças que emergem do estereótipo, sabe-se que parte da intervenção médica sobre a saúde da mulher foi reivindicada pelas próprias mulheres, num movimento "interno" a favor do reconhecimento de algumas condições como um problema médico, procurando-se áreas da vida da mulher onde a expansão médica fosse consensual para médicos e mulheres (Augusto, 2004; Conrad, 2007). Também a participação da indústria médica e farmacêutica tem de ser considerada nesta discussão, já que ambas, legitimadas pelas necessidades ora das mulheres, ora dos médicos, vão produzir e divulgar como imprescindíveis tecnologias cada vez mais complexas e mais dispendiosas.

Os movimentos de desmedicalização e de humanização da gravidez e do parto, embora com bases de reivindicação diferentes, têm promovido o direito a

3 O parto, em si, não depende da atuação profissional, não se podendo considerar um "ato médico". Nem mesmo a assistência não profissional de um parto ou a opção por um parto não assistido constituem, por si só, uma ilegalidade. 
alternativas ao modelo hospitalar predominante, alegando que, quando institucionalizado, o parto é habitualmente tratado como uma doença ou um problema a resolver medicamente, esvaziando-o da vida e da espontaneidade que o caracterizam. As parturientes, por seu turno, são desprovidas de identidade e consideradas inválidas, tabula rasa perante o ambiente de pericialidade hospitalar (Tereso, 2005; Shaw, 2007).

Transcendendo o controlo e a regulação exercidos pelo profissional de saúde sobre o corpo da mulher, sobre a gravidez e sobre o parto, existe ainda um controlo de manifestação mais subtil exercido pela sociedade, que se prende à própria construção social de género. Badinter (2010: 93) fala do "Império do Bebé" e descreve a ironia de uma "escravatura voluntária" a que as mulheres ocidentais, depois de se libertarem da dominância patriarcal, estão sujeitas quando são mães, numa sociedade onde se "privilegia a mãe em detrimento da mulher" (2010: 127). De facto, mais do que grávida, a mulher é responsável pela formação de um feto e essa responsabilidade ser-lhe-á imputada socialmente (Lupton, 1994). É esperado que seja "manager do próprio corpo" (Baudrillard, 2007 [1970]: 149). Como reforça Tereso (2005), a diminuição do número de filhos por casal transforma cada gestação não apenas num acontecimento delicado para os futuros pais, que procuram controlar todos os riscos, mas também num acontecimento social e político de que depende o futuro da própria humanidade. O seu corpo grávido é menos uma propriedade sua e mais o lugar onde se procuram criar as condições adequadas para o desenvolvimento do indivíduo que há de nascer (Tereso, 2005; Joaquim, 2006), e quer o desafio ao conhecimento médico, quer o incumprimento das normas por ele estabelecidas se tornam socialmente condenáveis.

A pericialidade, no entanto, como consequência do questionamento gradual dos processos de racionalidade científica, está em crise. Perante a modernização reflexiva (Beck, Giddens e Lash, 2000 [1994]), a medicina e as tecnologias médicas vão perdendo parte do seu valor inquestionável e sagrado e vão-se aproximando da prestação de serviços, constituindo apenas uma das várias hipóteses disponíveis (Saks, 1994). Apesar de, na prática, tal não significar uma crise real no modelo biomédico (Baudrillard, 2007 [1970]; Giddens, 2008 [1989]), obriga a repensar o poder e a reformular o papel atribuído a cada ator social no encontro profissional-doente (Lupton, 1994; Zadoroznyj, 2001). Sob a retórica do direito à saúde, a crescente acessibilidade aos serviços médicos, embora desigual, aproximou, como nunca antes, o recurso à tecnologia médica da lógica do direito ao consumo (Baudrillard, 2007 [1970]). Perante isto, a incerteza, a perceção do risco e a ausência de verdades absolutas tornam questionável a prática obstétrica hospitalar comum, reivindicando-se um diferente patamar de consentimento informado, em que se rejeita o obstetra como único detentor do conhecimento sobre o parto e se procura um patamar em que todos partilhem e discutam o conhecimento sobre o parto com a mesma legitimidade (Zadoroznyj, 2001; Cheyney, 2008).

De uma forma global, veem-se surgir outros modelos explicativos da saúde e dos processos que a envolvem, que procuram afirmar a sua autoridade, divulgando, por oposição à medicina, o seu caráter natural e holístico (Saks, 1994), o que também se tem vindo a verificar na gravidez e no parto. Badinter (2010) 
aborda, a partir de uma perspetiva crítica, a revalorização social do naturalismo. Para a autora, o retorno ao natural e ao tradicional é uma reação social às incertezas causadas pelos avanços e recuos da ciência e à indefinição de papéis de género. $\mathrm{O}$ modelo naturalista radical assume-se como oposto ao capitalismo, à tecnologia e à ciência, enaltecendo os valores de harmonia e respeito absoluto pela Natureza. No que respeita às mulheres e à maternidade, é possível assistir, na sociedade ocidental atual, ao louvor do instinto maternal e à emergência do ideal de "boa mãe ecológica" (Badinter, 2010: 41), que celebra o natural, rejeita o químico, e segundo o qual as respostas da ciência para determinadas condições das mulheres, definidas como problemáticas, seriam algo a rejeitar. Partindo desta perspetiva, há uma oposição declarada ao modelo hospitalar de assistência ao parto e uma aproximação ao contexto familiar, tradicional e natural de parir em casa. A relação com a dor no parto é bipolarizada: em contextos culturais mais próximos da natureza, a dor do parto é uma dor boa, por ser natural e permitir uma vivência integral da experiência de parir, enquanto a dor provocada por uma intervenção médica não fundamentada ou não consentida já não é bem acolhida. A epidural, por seu turno, integra o grupo de "armas suicidárias" (id., ibid.: 41), composto pelos produtos químicos e estratégias farmacológicas, e falsifica a real vivência do parto. Assim, seguindo os argumentos da autora, será em casa que a mulher poderá desfrutar de um encontro com o seu corpo e com a natural experiência de parir, sem as interferências da medicina.

O recurso a, ou a recusa da tecnologia obstétrica revelam-se enredados numa complexidade de fenómenos e de pressões, frequentemente díspares. A simples existência e divulgação de uma nova tecnologia obstétrica é condição suficiente para a promover e a sua recusa é comummente adjetivada como irresponsável e retrógrada. No entanto, constata-se que o uso atual de tecnologias excede frequentemente o necessário para a vigilância da saúde na gravidez, situando-se assim numa posição central na lógica do consumo, seja motivado pela perceção dos riscos sociais e médicos da gravidez e do desenvolvimento intrauterino, seja pela possibilidade de se aceder à conveniência e ao interesse pessoal da mulher grávida ou dos profissionais de saúde. Enquadrando a representação social do corpo da mulher como um recipiente para a maternidade, e o próprio bebé como um objeto de consumo, sujeito a testes de controlo de qualidade, são geradas fortes expectativas sociais de uma gravidez resultar num bebé perfeito (Ettorre, 2000). Existindo e estando disponíveis tecnologias obstétricas, são criadas pressões, por parte dos pares, dos profissionais de saúde e da indústria médica, sobre a opinião da grávida ou do casal para que não abdiquem do seu consumo (id., ibid.).

Em ambiente hospitalar, o consumo de tecnologias no parto é evidente, por exemplo, pelo recurso à indução medicamentosa do trabalho de parto e à cesariana eletiva. Marca-se o dia e a hora para o parto porque a grávida e/ou o profissional demonstram estar já cansados da gravidez, ou porque se quer fazer coincidir o parto com o dia de trabalho do obstetra, ou porque já se calculou o mapa astral para aquele dia e aquela hora, em que a conjuntura astrológica era a mais favorável. Todos estes motivos foram já enunciados em serviços de obstetrícia, com maior ou 
menor grau de discrição. ${ }^{4}$ São razões bastantes, numa lógica de consumo, para que se intervenha na gravidez e se aumentem consideravelmente os riscos num parto que, eventualmente, teria todas as condições para decorrer com um mínimo de intervenção médica.

Mais do que complexo, o consumo de tecnologias obstétricas revela-se paradoxal. Por um lado, reconhecem-se e divulgam-se amplamente os riscos da gravidez e do parto para a própria grávida e para o seu corpo, para o bebé e, consequentemente, para a sociedade; desenvolvem-se mecanismos de vigilância e tecnologias de controlo desses riscos; e criam-se respostas sociais que permitam atenuar as desigualdades no acesso a essas tecnologias. Por outro, publicitam-se tecnologias mais avançadas para um diagnóstico do risco mais preciso e mais caro; e recorre-se a intervenções mais iatrogénicas, com mais riscos e mais dispendiosas, por opção da mulher, do obstetra ou de ambos, aprofundando insidiosamente as desigualdades sociais. A lógica do consumo e a reflexividade individual da mulher grávida verificam-se quer no recurso à tecnologia obstétrica, quer na recusa de a utilizar. Por existirem ideologias ou fundamentações diferentes, desde as que se aproximam mais do "natural" e do místico, às que se afirmam pela sobredosagem tecnológica, há uma diversidade de opções quanto ao uso da tecnologia, todas elas ilustrando a procura de um parto perfeito e de um bebé normal.

\section{O trabalho de campo}

O percurso inicial de investigação empírica foi orientado por questionamentos em torno da opção pelo parto em casa e pelos aspetos que a enformam. Tomando como referência o cariz exploratório desta investigação, optou-se por uma metodologia qualitativa, já que se pretendia conhecer os processos de criação da experiência social e a sua significação (Denzin e Lincoln, 2011 [1994]), ou seja, conhecer em profundidade a realidade do parto em casa, desde um ponto de vista subjetivo - de quem optou e experienciou um ou mais partos domiciliares. Para que fosse possível aceder a estes fenómenos subjetivos, neste caso apenas compreensíveis através da linguagem (Ghiglione e Matalon, 2001 [1992]), e porque importava captar o discurso dos entrevistados que surgisse da sua própria linha de pensamento (Ruquoy, 1997 [1995]; Guerra, 2006), a técnica de recolha de dados que emergiu como a mais adequada foi a entrevista semidiretiva, realizada à mulher ou ao casal. Realizaram-se 18 entrevistas, oito delas em casal, que foram gravadas, com a duração média de 1 hora e 25 minutos. As entrevistas decorreram entre março e abril de 2012, nos distritos de Braga, Vila Real, Porto, Coimbra, Lisboa, Setúbal e Faro, sendo dez delas realizadas no distrito de Lisboa.

Foram descritos 34 partos com diferentes graus de profundidade, sendo oito deles partos hospitalares ( $\mathrm{PH}$ ) e 26 partos em casa (PC). Os partos domiciliares

4 Estes exemplos foram vivenciados por Mário J. D. S. Santos num serviço hospitalar de obstetrícia em Portugal. 
ocorreram entre 2005 e 2011. ${ }^{5}$ As experiências hospitalares foram principalmente descritas como contrastando com a experiência domiciliar, ou como legitimadoras, por si só, da opção pelo domicílio no parto seguinte. No entanto, o nível de profundidade da descrição destas experiências não permitiu uma análise comparativa entre as experiências de parto num e noutro local. Como tal, e em linha com os objetivos iniciais da pesquisa, a análise centra-se na experiência de um ou mais partos domiciliares.

\section{O lugar da pericialidade médica e da tecnologia}

A partir das entrevistas acedeu-se a um discurso repleto de terminologia médica (episiotomia, rolhão mucoso, período expulsivo, trabalho de parto), não só porque, como parte do processo de medicalização, a linguagem médica tem ganho protagonismo no discurso leigo e quotidiano, mas também porque esta confere legitimidade, pela sua cientificidade, ao discurso leigo e à opção de um parto em casa, podendo assim discutir-se com profissionais de saúde e contestar, na mesma base linguística, as práticas hospitalares de assistência na gravidez e no parto. À semelhança do descrito por outros autores (Viisainen, 2000; Conrad, 2007; Miller, 2009), o sistema pericial médico enforma o discurso, está na base de alguns dos procedimentos e constitui um recurso na gestão do risco. O conhecimento científico, no geral, e a linguagem médica, em particular, contribuíram para a legitimação das opções e das tomadas de posição da mulher ou do casal em relação aos procedimentos instituídos, uma marca que se enquadra no conceito de modernização reflexiva discutido por Beck, Giddens e Lash (2000 [1994]). Tal não pode ser entendido como independente da elevada escolaridade das participantes do estudo. Legitimada a visão do parto como algo fisiológico e rejeitando que se trata de algo patológico e, logo, dependente de intervenções médicas, o parto é descrito como algo simples, como parte da vida, como não sendo mais arriscado do que qualquer outro momento da vida. A pericialidade hospitalar é rejeitada, por ser um impedimento ao exercício do poder e do controlo da mulher sobre o seu corpo a parir:

Para além de a gravidez ter corrido tão bem e eu sentir que não ia lá [ao hospital] fazer nada. Quer dizer... Basicamente, eu para parir, precisava de tempo, precisava de um sítio qualquer, precisava que não me mexessem, que não me falassem, que não me incomodassem e para isso eu estava em casa. Fora todas as outras coisas que eu não queria que me fizessem e que me iam impossibilitar de ter no hospital. [Mariana, 33 anos, $1 \mathrm{PC}]$

Ao hospital é ainda associado um grande grau de incerteza, por referência à perda de confiança nas equipas hospitalares, a quem são atribuídas fragilidades e limitações

5 Para mais detalhes sobre os modos de seleção das participantes no estudo e sobre a sua caracterização, recomenda-se a consulta da dissertação de mestrado. 
por também haver partos que "acabam mal". Esta constatação vai ao encontro do que é referido por Giddens (1998 [1990]) e Zadoroznyj (2001) sobre as reconfigurações das relações de confiança nos sistemas periciais e, em particular, nos profissionais de saúde no parto, modeladas por elementos de reflexividade, por um lado, e por pressões sociais de normalização e responsabilização individual, por outro. Aqui, dado o reconhecimento da falta de legitimidade de alguns dos procedimentos hospitalares de rotina, a experiência de falta de liberdade e de autodeterminação pessoal da mulher no parto, e a constatação da primazia atribuída ao cumprimento de procedimentos e de normas hospitalares, a perceção do risco de um parto era maior no meio hospitalar do que em casa e isso despoletava, em última instância, a decisão pelo parto domiciliar. Mais, já com a decisão tomada em relação ao parto domiciliar, a ida para o hospital permanecia sempre como um receio e foi um dos aspetos mais vezes mencionado.

A própria relação com a morte assume contornos particulares. Tereso (2005) explica como a diminuição de filhos por casal tornou cada gravidez num acontecimento repleto de expectativas e de riscos. Aqui, paradoxalmente, quando se perguntava sobre os riscos reconhecidos à opção de parir em casa, a morte era verbalizada como uma possibilidade e aceite como tal. Em alguns casos, a morte do bebé era um medo presente no parto, noutros casos foi referida como algo que se aceitou como possível no planeamento do parto e no parto, mas que não esteve racionalmente presente nesses momentos:

Pode-se morrer num parto. Tenho perfeita noção disso. Acho que faz parte da vida. [Rita, 28 anos, 1 PC]

A opção pelo parto em casa é construída sobre um processo reflexivo de apropriação leiga de conhecimento e de linguagem científica que mune a mulher ou o casal de uma capacidade de argumentação legitimada pela ciência e que, em muitos casos, os próprios peritos não conseguem acompanhar, limitando-se a uma rejeição perentória das propostas e das opções apresentadas. Os profissionais perdiam assim, em definitivo, a confiança e a sua credibilidade pericial, como refere uma mulher sobre a sua visita ao hospital, na sua terceira gravidez:

Já tinha investigado e a minha ideia era eu poder circular, eu poder andar durante, durante as contrações e poder parar se me apetecesse e poder relaxar como, como eu sentisse que devia relaxar. E ter, por exemplo, a bola [de Pilates] para me sentar, para me sentir mais confortável e tudo isso e... Quando eu estava no quarto e faço essa pergunta [à enfermeira que conduzia a visita], primeiro eu vi que o espaço, sim senhor, eu podia ter a bola, até dava para ter ali, sim senhora. [...] E eu perguntei: “Mas e se eu me quiser levantar da cama, posso? - Mas levantar-se? - Sim, se eu não estiver confortável deitada e quiser estar em pé, estar encostada à cama, estar sentada... - Ah, não... Não, então mas vai estar ligada ao CTG!” E eu: “Sim, mas o fio pode esticar ligeiramente, posso ao menos dar dois passos para cada lado? - Ah, pois, não, mas isso, não, tem de estar deitada." E eu pronto, OK. [Cristina, 34 anos, 2 PH e 1 PC] 
Não obstante a rejeição do modelo hospitalar hegemónico de assistência no parto, durante a gravidez valorizou-se o acompanhamento por um ou mais profissionais de saúde e recorreu-se à tecnologia médica na avaliação e controlo dos riscos, embora não houvesse, habitualmente, um cumprimento absoluto do que está definido como a vigilância normal da gravidez. O modelo que predomina, ainda assim, é o acompanhamento médico habitual a nível público, no centro de saúde, ou a nível privado. Reconhecendo, também neste caso, o risco moral da opção pelo parto em casa, a opção era geralmente mantida em segredo perante a figura do obstetra ou do médico de família, profissionais que se orientam pelo modelo de parto hospitalar. Ao medo de condenação moral, acrescia o medo de represálias, quando o médico que fazia as consultas também podia ser encontrado no hospital. Quando a opção era comunicada ao médico, a reação mais frequente foi a condenação mas, inesperadamente, nem sempre a reação do médico era concordante com a expectativa:

R: Eu gostava de lhe ter dito, só que, por um lado, eu receei um bocadinho a reação dele. Porque pensei: “Ó pá, ele se calhar, à última da hora, é capaz de me dizer que eu tenho pouco líquido, ou que a bebé está pequena, ou que está grande demais e depois vai-me obrigar a, tipo, a... Ou induzir a que eu tenha um parto hospitalar." E por isso, na primeira gravidez, optámos por não lhe dizer nada.

M: Sim.

R: Depois, ele... Eu fui lá no pós-parto e ele foi muito simpático e "Ah, então, já estava a pensar o que é que lhe teria acontecido" porque já tinham passado as 42 semanas, não é? Então, eu disse-lhe que tinha tido em casa e ele "Ah, então um parto à holandesa, não é?" [risos].

M: Depois apresentou-nos à equipa toda como a holandesa, os holandeses. Houve ali uma receção boa. [Raquel, 32 anos, e Marco, 32 anos, 1 PC]

A reação, real ou esperada, dos médicos face à opção pelo parto em casa, conjugada com a incapacidade ou indisponibilidade para compreender a não aceitação de algumas das suas prescrições contribui para a degradação da confiança no modelo médico e hospitalar. Reconhece-se que a medicina e o ambiente hospitalar por ela configurado estão vocacionados para a intervenção e para a prescrição, e não para o aconselhamento e a negociação.

\section{Confiança e risco na gravidez e no parto}

Dentro da maioria que opta pela vigilância médica mais comum durante a gravidez, é frequente um acompanhamento paralelo pela enfermeira/parteira, que é descrito como mais personalizado, complementando a vigilância pré-natal e tornando-a, no conjunto, mais abrangente. Por oposição ao seguimento médico, mais impessoal, no percurso de definição da opção por um parto em casa e durante a gravidez é construída uma relação alicerçada na confiança com a equipa que assiste ao parto, por ser reconhecida como mediadora no processo de integração da gravidez e contribuir para a conquista de um sentido de coerência identitária. A par da 
informação científica mobilizada, a presença da enfermeira/parteira é um argumento usado como legitimador da opção perante a família, os amigos e os próprios médicos. É comum a referência à doula, uma figura emergente no panorama da saúde materna que não está enquadrada enquanto profissional de saúde. Habitualmente, possui uma formação orientada para a prestação de apoio emocional e de informações que, em grande medida, incorporam informação médico-científica da área, combinada com uma abordagem holística, contrastando com a abordagem médica mais comum. A doula pode ser enquadrada como uma conselheira perinatal e, habitualmente, o seu apoio é mobilizado durante a gravidez, o parto e o pós-parto. É de referir que, quando existe, a figura da doula emerge pela relevância do acompanhamento e da informação dados ao longo da gravidez, que medeia o processo reflexivo de construção da opção, sendo, em alguns casos, mais notória a complementaridade entre o médico e a doula, do que entre o médico e a enfermeira/parteira:

J: Fiz tudo, ou seja, tinha o acompanhamento hospitalar que elas aconselham sempre, nunca houve nenhum nem ninguém que tivesse dito o contrário, e depois tinha o, aquele acompanhamento mais específico e mais personalizado da parte da minha doula e da minha enfermeira. A única coisa que elas, que a minha doula dizia era: "Se não quiseres tomar os medicamentos que são químicos, o..."

E: O ferro, o ácido fólico...

J: Exatamente. “Come bananas, ou cereais. Alteras uma coisa pela outra e escusas de estar a ingerir químicos." Eu nunca tomei esses medicamentos, aliás comecei a tomá-los no início, ainda não sabia. A minha doula falou comigo, eu pus de parte e comecei a ter uma alimentação mais, com mais ferro e com mais legumes e com mais coisas. Todas as minhas análises estavam excelentes, nunca disse à minha médica. A minha médica disse: "Bem, as suas análises estão excelentes, tem tomado o ferro que lhe dei?"

E: Tenho sim senhora.

J: Tudo tranquilo. E não tomei nada, nunca tomei nada disso. Pronto lá tive as minhas, as minhas consultas, fiz tudo, só alterei isto. [Joana, 36 anos, 1 PC]

Não existe, portanto, uma rejeição do modelo biomédico, mas uma seleção reflexiva de qual deve ser o espaço ocupado pela biomedicina na gravidez, fazendo sobressair os conceitos de consumo e de manager do corpo (Baudrillard, 2007 [1970]). Com base num grande número de recursos disponíveis, quer do sistema médico e convencional, quer de um sistema alternativo, há uma definição personalizada de quais os recursos a mobilizar para que a vivência da gravidez ganhe sentido e seja integrada no self. A modalidade adotada para o acompanhamento médico da gravidez varia entre a mulher que cumpre todo o programa normal de consultas médicas e apenas rejeita uma ou outra indicação médica, como um suplemento ou uma análise, e a mulher que faz apenas uma consulta médica no início da gravidez e vai fazendo, depois, os exames que entende necessários.

Estas escolhas não significam uma rejeição do conhecimento científico, em favor de um conhecimento mais "tradicional" ou "popular", uma vez que são, em 
grande medida, escolhas fundamentadas com a pesquisa de conhecimento científico e legitimadas pela confiança na parteira ou na doula. São evidentes diferentes perceções do risco que se confrontam no encontro entre o médico e a grávida. De facto, em alguns casos, mais do que desnecessárias, algumas prescrições médicas foram vistas como arriscadas. Noutros casos, as recomendações fizeram sentido, mas foram adaptadas de modo a poderem ser integradas no conjunto das opções de vida anteriores. Noutros casos ainda, simplesmente não foram aceites, porque a compreensão do corpo fez sentir que estava tudo bem. A seguinte descrição representa de forma significativa o consumo de tecnologias médicas na gravidez:

R: Eu não queria ser tocada. É desnecessário. Muitos vão tocar para ver se está, se não está, se está quase, mas não é por aí que vou... Achei que não era necessário. E se eu sentia o bebé, estava sempre a mexer, sentia-me bem, sentia que estava tudo bem, não sentia que havia necessidade. Também percebi também de toda a pesquisa que o CTG demonstra o estado da mãe e do bebé nesse determinado momento. Não quer dizer que no parto possa estar melhor ou pior, não é? Então não fazia sentido eu estar a sair da minha rotina e estar a deixar de fazer coisas ou pôr isso e ir para lá, quando realmente não havia, também não estava a planear ter no hospital. Não fazia sentido.

E: Houve mais alguma coisa [...]?

R: Não, acho que não... [...] Acho que não tomei o ferro. Mas... tomei um ferro... comecei com um ferro e ácido fólico proveniente de um meio mais... de ervanária. ... Pois, recomendações, sim, houve assim algumas coisas que eu não fiz: não comer chouriço, não comer presunto, ter cuidados com os ovos, aa... Esse tipo de coisas, eu fazia o que o meu corpo me pedia. Tinha cuidado com as saladas e lavava as saladas por causa da toxoplasmose. [Ronalda, 31 anos, 1 PH e 1 PC]

De facto, o que mais frequentemente é alvo de rejeição é a toma de medicamentos e suplementos, como o ferro e as vitaminas, o que se procura compensar com a alimentação ou a toma de suplementos naturais, não químicos, lembrando o que Badinter (2010: 39) conceptualiza sobre a maternidade ecológica e a demonização da química, por encarnar "o artificial que, por definição, é inimigo do natural". No polo oposto, são consensuais a utilidade e a importância do recurso à ecografia, sendo a única tecnologia a que se recorre sempre, apesar de se reconhecerem riscos na realização de ecografias obstétricas em excesso, o que leva a que se rejeite a realização de mais do que três. ${ }^{6}$ Mesmo quando há uma rejeição completa das consultas médicas e das análises, não se prescinde da segurança dada pela realização de ecografias:

M: Na segunda gravidez nem fui a nenhuma consulta de obstetrícia, só fiz as três ecografias.

E: [...] O que é que te fez optar pelas ecografias e não pelas consultas, por exemplo?

6 É frequente a referência a médicos que prescrevem mais do que três ecografias obstétricas, embora a norma n. ${ }^{0}$ 023/2011 de 29/09/2011 da Direção-Geral da Saúde recomende a realização de apenas três, na vigilância de uma gravidez de baixo risco.

SOCIOLOGIA, PROBLEMAS E PRÁTICAS, n.ํํㄹㄹ 2016, pp.49-67. DOI:10.7458/SPP2016825922 
M: Ah, as ecografias porque queria ter a certeza que estava tudo bem com o bebé, não tinha malformações, tinha também... Porque eu achava desnecessárias, as consultas... Não sei o que é que elas me iam trazer de mais... o que é que elas iam ajudar a juntar àquilo que a ecografia revelava. Se estava tudo bem, porque é que eu havia de ir a uma obstetra? [Maria B, 32 anos, 2 PC]

De facto, como ilustra Ettorre (2000: 410), a relevância social da deficiência e a pressão exercida pelos mecanismos de controlo da reprodução conduzem a mulher na procura do estatuto da "boa reprodutora" que concebe um bebé normal. A imprescindibilidade do rastreio ecográfico entre os casos estudados denuncia a conformidade com estes mecanismos e demonstra o impacto das persistentes perceções de risco médico e social associadas à possibilidade de se ter um bebé imperfeito, com malformações. Mas além do seu potencial diagnóstico, esta relação com a ecografia aproxima-se também da proposta de Petchesky (1987) e de Lupton (2013), que descrevem a construção social das imagens do feto como objetos culturais, que excedem os propósitos médicos originais e englobam processos de personificação do embrião/feto, reconfigurando historicamente os seus estatutos sociais.

Há, de resto, um grande número de recursos mobilizados reflexivamente durante a gravidez e que foram referidos como parte do percurso de acompanhamento desta, como as sessões com a doula, os cursos sobre a gravidez e o parto, os encontros de casais, o yoga e os cursos mais comuns de preparação para o parto. Estes recursos são apresentados como um meio para o desenvolvimento de aspetos que o acompanhamento habitual, com um profissional de saúde, não permite desenvolver, complementando-o e contribuindo, também, para a já referida integração da gravidez no self. No entanto, o curso de preparação para o parto emerge como o recurso que, nos casos em que foi mobilizado, não contribuiu ou contribuiu pouco para essa integração:

Sinceramente, [o curso] a mim não me ajudou em nada, até por, eu acho, pela quantidade de informação que já tinha, não é? Mas, portanto, isto tinha sido num parto anterior. Mas tive noção que tudo aquilo que, pronto, também temos de ver que um curso de preparação para o parto é preparação para um parto hospitalar, não é? E eu acho que parte muito da ideia... É um bocado paternalista. Eu acho. Porque quando entramos aqui nas questões do como respirar e não-sei-quê, epá!... Só quem não, pronto, só quem não teve um parto assim, como eu tive, natural, é que acha que é preciso que nos ensinem a respirar. Eu acredito que, se calhar, num parto hospitalar, naquelas condições, pronto. É útil. Para quem tem um parto desses, talvez seja útil. Mas realmente aquilo que eu me apercebi pelo meu parto é que se tivermos as condições certas, esse ambiente propício, é inata a maneira como respiramos, a posição que procuramos. Ela não nos precisa de ser ensinada. [Jasmim, 39 anos, 1 PH e 1 PC]

O curso é referido em moldes que permitem enquadrá-lo como um mecanismo de regulação moral e de controlo do comportamento no parto, definindo-se como respirar, como se movimentar, como o companheiro pode ajudar e, no limite, como parir no hospital. O parto é descrito como uma experiência concreta de 
reconhecimento do corpo e, por isso, o curso é caracterizado pelo sentido de incoerência que promove em quem o frequenta e quer ter um parto em casa.

Também no parto foi feita referência à relevância e ao papel de cada um dos atores que estavam ou que deveriam ter estado presentes. Na sua maioria, foi referida a presença do outro membro do casal, da enfermeira/parteira e da doula, e é possível distinguir os papéis atribuídos a cada um.

Recuperando o conceito de gineceu, a que se recorre para ilustrar a exclusão do homem do local do parto nas sociedades tradicionais (Carneiro, 2008), identifica-se no parto domiciliar um gineceu reconfigurado, onde não tanto o género, mas principalmente as relações de confiança definem as condições de acesso. Neste sentido, também o papel do homem surge com configurações distintas, sendo reconhecida importância ao seu apoio emocional, ainda que lhe seja reconhecido, maioritariamente, um papel instrumental na preparação do espaço físico. Por um lado, esta reconfiguração afasta o homem da posição dominante que, em traços gerais, lhe é reconhecida numa sociedade patriarcal. Por outro, afasta-o do papel passivo e expectante que tradicionalmente lhe é atribuído no parto.

À parteira é atribuído um papel pericial, sendo-lhe reconhecida uma autoridade carismática configurada pelo saber científico, combinado ou enriquecido pelo "saber de experiência feito". À doula é atribuído um papel familiar ou maternal. Habitualmente, quando se inicia o trabalho de parto, o primeiro contacto telefónico é com a doula e, em alguns casos, a doula e a enfermeira/parteira são contactadas em simultâneo, mas nunca o contrário. Não foi possível esclarecer empiricamente o que leva a esta distinção.

\section{Incorporar a experiência do parto}

O início do trabalho de parto e o parto surgem como uma experiência concreta (e não mística) de incorporação de um processo que é fisiológico ou natural. A autodeterminação, o instinto, a confiança no corpo e a interpretação e compreensão dos seus sinais são eixos condutores da experiência de parir. A referência ao instinto confere naturalidade ao parto e aproxima a experiência da mulher da experiência dos restantes mamíferos:

Eu tive a sensação que nós nos tornamos um bicho autêntico. Em casa, eu posso-lhe descrever, no parto da minha primeira filha, eu gosto muito de ouvir música e pus música quando comecei, mas durou muito pouco tempo, porque a seguir o que eu queria era silêncio, escuridão e quentinho. E pedi até ao marido para pôr o colchão na sala, veja lá. Ele pôs-me o colchão na sala, ligou os aquecedores todos e eu fiquei ali, no escuro, apaguei as luzes, pus tudo em silêncio e o que eu senti era, eu acho que deve ser aquilo que sentem os mamíferos quando vão para a toca para ter os seus filhos. [Jasmim, 39 anos, 1 PH e 1 PC]

Não obstante, a tomada de consciência de que o parto estava próximo nem sempre foi despoletada por um sinal físico do corpo, que é o que se verifica com a maioria. Num conjunto minoritário, mas significativo, há sinais subjetivos que são descritos 
como tendo permitido intuir o início do trabalho de parto, tal como a fase da Lua (lua cheia), a "despedida da barriga" ou a "síndrome do ninho", estes últimos revelando não só a intuição da mulher, mas o seu poder de decidir quando está preparada para o parto:

Só comecei a arranjar as coisas muito tarde, a preparar as coisas para o bebé muito tarde, então achava que ele nunca ia nascer enquanto eu não tivesse tudo preparado, que eu inconscientemente não ia deixar aquilo acontecer. E então, a certa altura, falei com a minha doula e disse-lhe: “Olha, ele nunca mais nasce.” Já estava com quarenta e uma semanas, e ela disse: “Estás muito confortável nisso, não estás?" E eu: “Sim, eu acho que não me está a apetecer agora deixar de ficar grávida. Agora estou aqui nisto!" E ela disse: "Pois, tens de te despedir da barriga." Então fiz assim uma despedida da barriga, assim, fui passear, despedi-me da barriga, tirei muitas fotos e depois, um dia depois ou dois dias depois, eu passei uma tarde assim em casa a ver um filme [...] e comecei a sentir as contrações. [Lassa, 34 anos, 1 PC]

Os sinais físicos surgem de seguida, nestes e nos restantes casos, confirmando a proximidade do parto através de contrações rítmicas, dores, a saída do rolhão mucoso e a rotura da bolsa de águas. Partindo daqui, cada pessoa revelou uma experiência singular do trabalho de parto, refletindo a liberdade e a autodeterminação da mulher, sendo adotadas diferentes posições, diferentes locais em casa e diferentes estratégias para o alívio da dor, com diferentes durações, diferentes equipas e diferentes níveis de aceitação da tecnologia, uma diversidade incompatível com a normatividade hospitalar. $O$ parto em casa conduziu a um afastamento simbólico de uma realidade coletiva e a uma aproximação a uma realidade mais individualizada, através do embodiment (Lupton, 1994) do processo de parir:

Sinto que me foi proporcionado um contacto comigo própria e com o meu corpo que era difícil eu ter noutro lado qualquer. Que me foi proporcionada a possibilidade de eu ter uma consciência corporal mais aguçada. Não sei se me... Se faz algum sentido ou se consegues compreender. [Madalena, 32 anos, 2 PC]

A dor no trabalho de parto foi largamente descrita com o recurso a expressões como "insuportável", "horrível", "ossos a rasgar" e, em alguns casos, como "importante". Contrariando Badinter (2010), não lhe é reconhecido um valor positivo por ser natural, mas antes por tornar o processo inteligível e permitir a perceção consciente do corpo, para que se possa exercer o controlo:

Eu também acho que a dor é importante para saber o que se está a passar. Por isso eu gosto muito de sentir a dor. Eu nunca quis levar epidural porque acho que se apaga a dor e nós não sabemos o que se está a passar no nosso corpo. E para mim é muito importante saber o que se está a passar. Mesmo quando há a coroação do bebé, dói bastante no períneo, mas eu prefiro sentir essa dor e saber se está a rasgar ou não, do que não sentir nada e, por exemplo, irem-me cortar. [Rita, 28 anos, 1 PC] 
Ainda assim, dentro da descrição concreta do trabalho de parto, através do que acontece no corpo e no espaço envolvente, foi referida uma experiência menos concreta, identificada como "partolândia" ou "transe" ou um "processo iniciático onde é possível contactar com o mundo espiritual":

Enquanto estive na banheira, estava na partolândia, completamente. Eu não faço ideia de quanto tempo foi, eu não me lembro de ter dores, lembro-me de ser um parto muito intenso. [Mariana, 33 anos, 1 PC]

Eu acho que nós quase que ascendemos a outro nível da... Eu nem posso falar disto, que fico um bocado emocionada... A outro nível da existência. É fenomenal. Eu não sou nada religiosa, nem esotérica, nem nada, mas se há alguma parte da nossa vida em que nós tenhamos algo de divino, acho que é naquele momento e o passar de todo aquele processo. [Jasmim, 39 anos, 1 PH e 1 PC]

Esta descrição de um período de transcendência onde é atingido um outro estado de consciência e de onde, por vezes, não é possível resgatar a memória do que concretamente aconteceu, constitui o único elemento de misticismo ou esoterismo que foi possível identificar.

\section{Consumo reflexivo da tecnologia e controlo}

O controlo de todo o processo assume contornos importantes, já que, além de à dor, também à tecnologia é atribuído um valor moral, sendo boa ou má consoante o seu recurso dependa ou não da vontade da mulher, ou consoante o seu uso permita ou não a liberdade da mulher. Há um recurso frequente a tecnologias, como piscinas de parto, bolas de Pilates, bancos de parto, cardiotocógrafo ou doppler fetal, entre outras. Podemos considerar a existência de um continuum entre a aceitação completa e a rejeição completa da tecnologia, onde cada mulher se posiciona mais próxima ou mais afastada de cada um dos polos, não se verificando, mais uma vez, uma homogeneidade de posicionamentos. Houve apenas um caso em que se identificou uma rejeição praticamente total da tecnologia. A maioria dos casos posiciona-se num nível intermédio, incluindo-se a aceitação de instrumentos, como a bola de Pilates ou a piscina. Depois, com menos frequência, inclui-se a aceitação de substâncias que aceleram o parto ou que aliviam a dor, desde que sejam naturais. Houve quem descrevesse uma indução do trabalho de parto controlada por si e com recurso a métodos não farmacológicos, perante a ameaça de internamento para uma indução hospitalar feita pela médica:

Nessa sexta-feira decidi: “Não, isto de hoje não vai passar, eu não quero ir para o hospital, nem pouco mais ou menos." E então decidi ir sair com as minhas amigas. [...] Fui para um bar de praia, estive sempre a dançar, a dançar, a pular, a pular, que era para ver se aquilo... Ao pé da coluna, por causa da vibração, ao pé da coluna, a pular. Eram quatro, quatro e pouco, eu já estava a sentir a barriga muito dura e eu disse às 
minhas amigas: “Olhem, eu vou-me embora, já estou assim um bocadinho cansada, eu vou-me embora". [Joana, 36 anos, 1 PC]

Não parece ser o ambiente hospitalar que encerra a "tecnologia má", uma vez que, em casa, não se rejeita a mesma tecnologia quando ela é usada por opção da mulher ou por sugestão de outrem, desde que com a sua concordância. A confiança no contexto e na pessoa que aplica a tecnologia também não basta para a legitimar pois, mesmo quando acontece em casa e é feita pela parteira, se uma dada intervenção é entendida como desnecessária, é uma intervenção ilegítima. Mais, tendo tudo decorrido sem complicações no parto, o que corre mal é associado frequentemente a uma intervenção não desejada da enfermeira/parteira, como refere esta mulher sobre a repentina intervenção da parteira, que chegou pouco depois de o bebé nascer:

Apesar da parteira ser uma mulher muito interessante e eu achava-lhe muita graça, senti que ela me tinha retirado alguma coisa também. De repente tinha chegado ali e eu, que estava naquele processo todo-poderoso: “Eu consigo parir o meu filho, isto é um processo meu." E ela desata lá a fazer as coisas que achou que ela tinha de fazer e deixaram-me ali um bocado... [Filipa, 34 anos, 1 PH e 2 PC]

Avaliando a experiência do parto, "correr bem" não é corresponder às expectativas. Em muitos casos, o parto idealizado não aconteceu e, ainda assim, considera-se que correu bem. O facto de a parteira não chegar a tempo, o cordão partir e não permitir esperar que deixasse de pulsar antes de o cortar, ou o parto demorar mais tempo do que o esperado, entre outros fatores, não parecem influenciar essa avaliação. Também não se afigura como suficiente o facto de mãe e bebé estarem bem, já que, quando tal acontece no hospital, é referido que a experiência não foi completa ou que "faltou qualquer coisa". No conjunto, parece ser a apropriação da experiência de parir, o controlo sobre o processo e a autodeterminação que definem e configuram a experiência do parto em casa como uma experiência positiva.

\section{Conclusões}

Este artigo lança as bases para um retrato sociológico do parto domiciliar planeado contemporâneo. Pela análise das experiências descritas, ele afasta-se de alguns dos enunciados apriorísticos que o associam a uma recuperação de valores e modelos tradicionais, ou a uma experiência mística, espiritual ou esotérica. Em certa medida, afasta-se até do pressuposto de que este se enquadra no naturalismo, embora se verifique uma valorização do natural. Pelo contrário, o parto domiciliar caracteriza-se por um recurso reflexivo à ciência e ao conhecimento médico, onde apesar de se conhecerem os pressupostos da racionalidade técnico-científica, não se reconhece a primazia desta racionalidade. O parto é descrito como um evento concreto que acontece no corpo; e a mobilização de elementos tecnológicos médicos ou "alternativos", em algumas situações, modela e altera o que seria o desenvolvimento de um trabalho de parto e parto espontâneos, fisiológicos ou naturais. 
Estas características da modernização reflexiva - o consumo combinado de tecnologias obstétricas e alternativas, bem como a redefinição de relações com base na confiança e a constituição de um gineceu reconfigurado - revelam ser mais do que uma simples mobilização aleatória de todos os recursos acessíveis. Denunciam uma diversidade de perceções de riscos médicos e sociais em interação, que se distingue das perceções de risco que guiam a prática obstétrica predominante. No seu conjunto, definem um percurso de integração positiva das experiências no selfe de conquista de um sentido de coerência identitária.

Pode dizer-se que é esta incompatibilidade com os sistemas de vigilância e controlo impostos nas instituições hospitalares que conduz o parto num movimento de desinstitucionalização. Apesar de retirar poder e protagonismo à prática médica, a opção por um parto em casa não o transforma num acontecimento desmedicalizado e não reflete uma rejeição do modelo biomédico, mas antes uma recusa do monopólio e da hegemonia de saber e de ação da medicina sobre a gravidez e o parto.

\section{Referências bibliográficas}

Augusto, A. (2004), Infertilidade e Reprodução Medicamente Assistida em Portugal. Dos Problemas Privados aos Assuntos Públicos, Covilhã, Universidade da Beira Interior, tese de doutoramento em Sociologia.

Badinter, E. (2010), O Conflito. A Mulher e a Mãe, Lisboa, Relógio D’Água.

Baudrillard, J. (2007 [1970]), A Sociedade de Consumo, Lisboa, Edições 70.

Beck, U., A. Giddens, e S. Lash (2000 [1994]), Modernização Reflexiva, Oeiras, Celta Editora.

Campbell, C. R., e S. Porter (1997), “Feminist theory and the sociology of childbirth: a response to Ellen Annandale and Judith Clark", Sociology of Health E Illness, 19 (3), pp. 348-358, disponível em: http:/onlinelibrary.wiley.com/doi/10.1111/j.1467-9566.1997.tb00023.x/pdf (última consulta em junho de 2016).

Carapinheiro, G. (2005 [1993]), Saberes e Poderes no Hospital, Porto, Edições Afrontamento (4. ${ }^{\text {a }}$ edição).

Carneiro, M. (2008), Ajudar a Nascer. Parteiras, Saberes Obstétricos e Modelos de Formação - Séculos XV-XX, Porto, Editora da Universidade do Porto.

Cheyney, M. J. (2008), “Homebirth as systems-challenging praxis: knowledge, power, and intimacy in the birthplace", Qualitative Health Research, 18 (2), pp. 254-267, disponível em: http://qhr.sagepub.com/content/18/2/254.full.pdf+html (última consulta em junho de 2016).

Conrad, P. (2007), The Medicalization of Society, Baltimor, The Johns Hopkins University Press.

Denzin, N. K., e Y. S. Lincoln (2011 [1994]), “Introduction: the discipline and practice of qualitative research", em N. K. Denzin e Y. S. Lincoln (orgs.), The Sage Handbook of Qualitative Research, Thousand Oaks, CA, Sage Publications (4. a edição).

Ettorre, E. (2000), “Reproductive genetics, gender and the body: 'Please Doctor, may I have a normal baby?' ", Sociology, 34 (3), pp. 403-420, disponível em: 
http://soc.sagepub.com/content/34/3/403.full.pdf+html (última consulta em junho de 2016).

Euro-Peristat (2013), The European Perinatal Health Report - Health and Care of Pregnant Women and Babies in Europe in 2010, s.l., s.n., disponível em: http://www.europeristat.com (última consulta em junho de 2016).

Foucault, M. (1994 [1976]), História da Sexualidade I - A Vontade de Saber, Lisboa, Relógio D'Água.

Fox, B., e D. Worts (1999), "Revisiting the critique of medicalized childbirth: a contribution to the sociology of birth", Gender $\mathcal{E}$ Society, 13 (3), pp. 326-346, disponível em: http://gas.sagepub.com/content/13/3/326.full.pdf+html (última consulta em junho de 2016).

Ghiglione, R., e B. Matalon (2001 [1992]), O Inquérito. Teoria e Prática, Oeiras, Celta Editora (4. ㄹ edição).

Giddens, A. (1998 [1990]), As Consequências da Modernidade, Oeiras, Celta Editora (4. ํㅡ edição).

Giddens, A. (2008 [1989]), Sociologia, Lisboa, Fundação Calouste Gulbenkian (6. ㄹ edição). Guerra, I. C. (2006), Pesquisa Qualitativa e Análise de Conteúdo, Estoril, Principia.

Joaquim, T. (2006), Cuidar dos Outros, Cuidar de Si, Lisboa, Livros Horizonte.

Lupton, D. (1994), Medicine as Culture. Illness, Disease and the Body in Western Societies, Londres, Thousand Oaks e Nova Deli, Sage Publications.

Lupton, D. (2013), The Social Worlds of the Unborn, Basingstoke, Palgrave Macmillan.

Miller, A. C. (2009), “'Midwife to myself' ”, Sociological Inquiry, 79 (1), pp. 51-74, disponível em: http://onlinelibrary.wiley.com/doi/10.1111/j.1475-682X.2008.00272.x/pdf (última consulta em junho de 2016).

Olsen, O., e J. Clausen (2012), "Planned hospital birth versus planned home birth", Cochrane Database of Systematic Reviews, 9 (CD000352), disponível em: http://almenpraksis.ku.dk/nyheder/oleolsen/Hjemmef_dsel.pdf (última consulta em junho de 2016).

Petchesky, R. P. (1987), "Fetal images: the power of visual culture in the politics of reproduction", Feminist Studies, 13 (2), pp. 263-292, disponível em: http://www.jstor.org/stable/3177802 (última consulta em junho de 2016).

Riessman, C. K. (1994), “Women and medicalization: a new perspective”, em H. Schwartz (org.), Dominant Issues in Medical Sociology, Nova Iorque, MacGraw-Hill, pp. 190-230 (3.ㄹ edição).

Ruquoy, D. (1997 [1995]), “Situação de entrevista e estratégia do investigador”, em Luc Albarello et al. (orgs.), Práticas e Métodos de Investigação em Ciências Sociais, Lisboa, Gradiva, pp. 84-116 (2. a edição).

Saks, M. (1994), "The alternatives to medicine”, em J. Gabe, D. Kelleher e G. Williams (orgs.), Challenging Medicine, Londres e Nova Iorque, Routledge, pp. 84-103.

Shaw, R. (2007), “'It's your body, your baby, your birth': planning and achieving a home birth", Feminism Psychology, 17 (4), pp. 565-570, disponível em:

http://fap.sagepub.com/cgi/content/refs/17/4/565 (última consulta em junho de 2016).

Tereso, A. (2005), Coagir ou Emancipar?, Coimbra, Formasau.

Viisainen, K. (2000), “The moral dangers of home birth: parents' perceptions of risks in home birth in Finland", Sociology of Health E Illness, 22 (6), pp. 792-814, disponível 
em: http://onlinelibrary.wiley.com/doi/10.1111/1467-9566.00231/pdf (última consulta em junho de 2016).

Zadoroznyj, M. (2001), “Birth and the 'reflexive consumer': trust, risk and medical dominance on obstetric encounters", Journal of Sociology, 37 (2), pp. 117-139, disponível em: http://jos.sagepub.com/content/37/2/117.full.pdf+html (última consulta em junho de 2016).

Mário J. D. S. Santos. Assistente de investigação, Instituto Universitário de Lisboa (ISCTE-IUL), CIES-IUL, Av. Forças Armadas, 1649-026 Lisboa, Portugal.

E-mail: mjdss@iscte-iul.pt

Amélia Augusto. Professora auxiliar, Faculdade de Ciências Sociais e Humanas, Universidade da Beira Interior, Estrada do Sineiro, s/n, 6200-209 Covilhã.

E-mail: aaugusto@ubi.pt

\section{Agradecimentos}

Os autores agradecem a disponibilidade de Amélia Vicente e de Josefa Fernández López, que traduziram o resumo em francês e em espanhol, respetivamente.

Receção: 03-08-2015 Aprovação: 08-01-2016 
